\section{Knowledge Production for} All

\section{Alma Maldonado-Maldonado and Jenny J. Lee}

Alma Maldonado-Maldonado is researcher at the Departamento de Investigaciones Educativas (DIE)-CINVESTAV in Mexico City, Mexico. E-mail: almaldo2@gmail.com. Jenny J. Lee is a professor at the Center for the Study of Higher Education at the University of Arizona, Tucson, US, and a visiting scholar at the University of Cape Town, South Africa. E-mail: jennylee@email.arizona.edu.

$\mathrm{W}$ ho should be responsible for producing research and where should it take place? By allocating the role of creating knowledge to faculty employed at top institutional producers (as determined by their position in global university rankings), stratified higher education systems are perpetuated while participation in knowledge production is curbed. The current system is already challenged in terms of inclusivity and diversity. Preserving this vertical differentiation worldwide, in a context of widening higher education participation, may not be the best strategy when knowledge has been recognized as a key factor to combat inequalities in the world.

There are two major and related consequences to consider when limiting research locations. First, assigning the research function to select universities could affect the diversity of those who produce knowledge, thus limiting the breadth of knowledge produced. Across nations, faculty at these institutions tend to be less diverse in terms of gender, race, and class. Second, reserving the research function to any country's top research universities will inevitably increase stratification within countries.

Already, there is abundant research (including from scholars in nonresearch universities) documenting how individuals belonging to minority races and ethnicities and with a low socioeconomic status are disadvantaged in terms of access to higher education. In fact, research universities also have the most selective admissions procedures, limiting social mobility and favoring individuals from the highest socioeconomic strata, while disadvantaging ethnic minority students by relegating them to less resourced universities. These demographic concerns also apply to faculty.

Rather, research should be promoted across types of institutions, with greater efforts on strengthening as well as legitimizing local knowledge, thereby allowing scholars in less studied parts of the world to become part of the global dialogue. When people who produce knowledge are more diverse, there are more possibilities to expand on the kinds of questions that are asked, the methodologies that are used, and the possibilities for more varied approaches, interpretations, and even discoveries. The number of international coauthorships is increasing and this trend is also an effect of growing higher education participation worldwide and the way some emerging economies are actively increasing their role as knowledge producers.

\section{Evaluation and Dissemination}

Indeed, there is a crisis in publications, at least partly facilitated by pressures to publish. Related problems include Western biases in peer review and dominance in top journals worldwide. These two contextual elements should be considered in a broader discussion on research production and publications.

Faculty from top universities live under constant scrutiny by evaluation mechanisms oftentimes reflective of global rankings criteria. Universities expect these faculty to publish in top journals in English (which may not be their home language, and thus may not be read locally). Research with more relevance to the immediate context might not be measured as having high "impact." This widely accepted, but hardly questioned criterion of "impact," based on international citations alone, further advantages core players while marginalizing the rest. Universities need to reorient evaluation systems by stressing the importance of producing local knowledge that matters to the local context while informing global audiences.

\section{Assigning the research function to se- lect universities could affect the diver- sity of those who produce knowledge, thus limiting the breadth of knowledge produced.}

Accessing publications in top journals is restricted to the universities, organizations, and individuals who can afford them, leaving much of the world without access to this new knowledge and further reducing their ability to influence citation indexes. Democratizing knowledge production does not prevent problems originating from the saturation of publications around the world, predatory journals, or issues of plagiarism and ethics. Yet such problems do not get solved by sending the message to simply stop publishing. Rather, evaluation systems should also consider the value of local languages and the broader range of publication outlets.

\section{"Academic Capitalism"}

Inequality gaps are especially evident when research is 
commodified. According to World Bank data on payments and purchases of intellectual property by the United States, Brazil, Argentina, and Chile (Balance of Payment, US\$) during 20I7, the United States profited by US\$79 billion, whereas Brazil lost US\$4.5 billion, Argentina US\$2.I billion, and Chile US\$I.4 billion. This data demonstrates the unequal financial dynamics of the knowledge economy and exemplifies the importance of knowledge production for development. Intellectual property consumption results in a financial deficit for countries that create less knowledge. Given these current inequalities, maintaining the same global structure and the same national stratification, especially for low knowledge producers, is not the answer.

\section{Training Graduate Students}

Research and teaching do not have to be mutually exclusive and faculty work in these areas is not always zero-sum. Training graduate students is especially important in the current knowledge society. Students today must be skilled in the research process, whether or not they become academics, in order to recognize rigorous research as well as understand how to participate in it. Given the challenge for students worldwide to access top institutions as a result of stratification, knowledge creation should be a core educational component across all university types.

\section{Research Capacity Building}

In the current knowledge society, students and scholars, particularly in nonresearch universities, should learn how to be active contributors of knowledge, rather than mere consumers. Especially in low-income countries lagging behind in research production, capacity building should integrate research and teaching.

Additional promising strategies to build knowledge production capacity include investing in and monitoring research funding, creating reputable publication outlets and monitoring predatory journals - as well as educating students (undergraduate and graduate) about the difference-and rewarding meaningful research that addresses local needs and informs local and international audiences.

\section{FINAL REMARKS}

In sum, global knowledge production would be severely weakened if the recommendation of limiting the types of institutions or the categories of faculty conducting research was followed through. Moreover, simple solutions do not fix complex problems - and may create even worse challenges. The message cannot be to dissuade particular types of universities or categories of faculty from doing research. The problem with such utilitarian approaches is that they do not change the status quo and serve to justify cultural hegemony. Reducing the number of research publications may weaken the market for predatory publishers and might address some forms of corruption but would also limit the participation of marginalized groups. The future of research, teaching, and service is to be innovative, interdisciplinary, and borderless. Limiting research to elite universities will not change the current global order. At present, knowledge and wealth are inextricably linked; only if we start changing the dynamics of this order can we start reducing inequality gaps within and across countries.

DOI: http://dx.doi.org/ıo.60I7/ihe.2019.96.10787

\section{China-US Cooperation in Higher Education: A Critical Stabilizer}

\section{Gerard A. Postiglione and Denis Simon}

Gerard A. Postiglione is honorary professor and coordinator of the Consortium of Higher Education Research in Asia, University of Hong Kong, China. E-mail: gerry.hku@gmail.com. Denis Simon is executive vice-chancellor of Duke Kunshan University, China, and professor of China business and technology at the Fuqua School of Business at Duke University, Durham, US. E-mail: denis.simon@duke.edu.

A s the United States and China were engaged in normalizing relations in the late I970s, Chinese leader Deng Xiaoping became adamant that China should have "a thousand talented scientists" who would be recognized around the world. By "trumpeting the need for more qualified scientists and engineers," Deng wanted quick approval to send several hundred Chinese to study at top American universities. Over the past 40 years, diplomatic relations between the United States and China have steadily grown, even considering periodic strains over economic, political, and military issues. Expanded economic and financial interdependence along with finely tuned statecraft have ensured that cool heads prevailed in times of stress, and thus cooperation across a wide array of domains has seemingly kept expanding over the last several decades.

\section{Trumping Out a Thousand Talents}

Unfortunately, those days of relative calm and foresight may be ending abruptly thanks to the Trump-initiated trade war, which Alibaba's Jack Ma says, "may last for 20 years if it's unfortunate." And there are emerging signs that US-China cooperation in higher education may be in for a serious jolt for the first time in four decades. Even the- 